\title{
Deeper inside the Experience of Pediatric Headache: A Narrative Study
}

\author{
Licia Grazzi ${ }^{1}$, Venusia Covelli2 ${ }^{*}$ (), Francesca Memini², Paul B. Rizzoli ${ }^{3}$ \\ ${ }^{1}$ Headache and Neuroalgology Unit, Fondazione IRCCS Istituto Neurologico Carlo Besta, Milan, Italy \\ ${ }^{2}$ STORIOSS Research Centre, e-Campus University, Novedrate, Como, Italy \\ ${ }^{3}$ John R. Graham Headache Center, Department of Neurology, Brigham and Women's Faulkner Hospital, Boston, MA, USA \\ Email: *venusia.covelli@gmail.com
}

How to cite this paper: Grazzi, L., Covelli, V., Memini, F. and Rizzoli, P.B. (2020) Deeper inside the Experience of Pediatric Headache: A Narrative Study. Journal of Behavioral and Brain Science, 10, 432-454 https://doi.org/10.4236/jbbs.2020.1010028

Received: September 8, 2020

Accepted: October 27, 2020

Published: October 30, 2020

Copyright (c) 2020 by author(s) and Scientific Research Publishing Inc. This work is licensed under the Creative Commons Attribution International License (CC BY 4.0).

http://creativecommons.org/licenses/by/4.0/

\section{(cc) (i) Open Access}

\begin{abstract}
Objective: To explore meanings, perspectives and points of view of the subjective experience of paediatric patients with headache $(\mathrm{PPwH})$ and create a first-person narrative for clinical practice. Methods: We conducted a qualitative, narrative research study with $\mathrm{PPwH}, 11-17$ years old. Data were collected through narratives interviews and a twofold narrative analysis was performed: a narrative and a thematic analysis. Results: Twenty-three patients (14 girls; mean age 14.5; median duration of illness of 5.8 years) were recruited. Through narrative analysis and close reading, narratives revealed different ways to organize illness experience: $\mathrm{PPwH}$ can use 1) narrative sequences of recurrent events in order a) to describe the continuing living-through of the experience of headache, b) to define operative script or c) to characterize the illness experience generally as a "controlled" routine; or 2) a storied account of events, with well-defined characters, plot and evaluation of contingency and correlation between events to express a personal point of view and a moral standpoint about the illness experience. Through thematic analysis 5 main themes and 22 subthemes about the significance of being a PPwH emerged: a) disease dimension (description of pain), b) illness dimension, c) sickness, d) causality, e) coping and f) future perception. Then, a first-person narrative story was created as a tool enabling reflection and conversation during clinical consultation. Conclusions: Results suggest that promoting narrative dialogue can be an opportunity for the neurologist: the prototypical narrative developed from story analysis might be a tool to apply for the narrative-based medicine in the clinical setting.
\end{abstract}

\section{Keywords}

Paediatric Headache, Narrative Research, Illness Narratives, Narrative Medicine, Patients Perceptions 


\section{Introduction}

Headache is a prevalent clinical condition and has recently been ranked among the three leading causes of disability worldwide [1] [2]. Headache in paediatric patients is equally prevalent [3] and occurs in $9.1 \%$ of children and adolescents [4], a condition that often persists into adulthood [5]. Paediatric migraine becomes chronic if patients experience headache episodes for at least 15 days or more per month, and with at least 8 episodes of migraine classified as moderate to severe, pulsating and with associated symptoms of nausea, vomiting, phonophobia and photophobia [6]. About $1.75 \%$ of young people suffer from chronic migraine [7] and most of them experience severe difficulties due to their condition, including reduced school activity and quality of life [8]. A recent population-based study involving a large sample of adolescents in Italy [9] pointed out a similar prevalence, a considerable impact of headache on daily activities (nearly a half needed to give up daily activities or seek bed rest until the symptoms were over) and school-related stress as a main cause of headache episodes.

The impact of headache on various aspects of adolescents' lives has been investigated through qualitative studies and the collection of patient's experience of illness. These have included the role of the family and peers in the management of patients' health condition [10]: the impact of migraines on adolescents' social functioning (the need to be alone, the lack of support from siblings and the feeling of not being understood by others) [11], coping strategies carried out (both problem-focused active strategies and emotion-focused passive strategies to deal with their headache in daily life) [12] and the role of cognitive behavioural therapy in reducing headache frequency and related disability [13]. Similarly issues, such as compromised quality of life, effect on others, uncertainty and emotional impact arose from a recent systematic review of qualitative studies from a patient's perspective involving adult people with chronic headache [14].

The available qualitative studies support the need to consider the living experiences of paediatric patients with headache $(\mathrm{PPwH})$. A greater understanding of how PPwH comprehend and make sense of their experiences and concerns could result in improved outcomes and self-care. One way to better understand the psychosocial experiences of human beings is through narrative research [15], where narratives are a tool for understanding one's own and others' actions, for organizing events and objects and for attributing meanings. They express the narrator's point of view, by making the narrator's self the protagonist, both as an actor and as an interested observer of other people's actions [16]. Narratives used in healthcare research can set a patient-centred agenda; challenge received wisdom; generate new hypotheses. As suggested by the narrative-medicine approach [17] [18], through their stories, patients help health professionals to focus on their perceptions and experiences rather than directly applying a professional framework [19].

The aim of our study was twofold: 1) to explore meanings, perspectives and point of view of the subjective experience of paediatric patients with headache; 
2) to create a paradigmatic first-person narrative, to be used by neurologist in clinical practice for the collection of patient narratives. To the best of our knowledge, no previous qualitative studies on paediatric headache were realized from a narrative research standpoint and through the lens of narrative based medicine.

\section{Methods}

\subsection{Design}

Within the framework of qualitative research, a narrative research approach [20] [21] was chosen as the most suitable method to investigate the illness experience of $\mathrm{PPwH}$. This study refers to the principles of narrative medicine using people's disease stories in clinical practice [22] [23]. The approach of narrative medicine involves the collection of illness narratives through which patients organize and give meaning to their experiences of illness. The analysis focuses on the subjective relevance of events and the way narratives are reconstructed and transmitted. As in previous studies, the focus is on people who choose to say and how they structure their experience of illness [24] [25].

The study was approved by the ethical committee of the Neurological Institute C. Besta. Informed consent was obtained from parents/legal guardians prior to study participation; before starting the interview, assent was obtained from pediatric patients too.

\subsection{Participants}

Between May 2019 and October 2019, 23 pediatric patients aged from 11 - 17 years were consecutively recruited for participation in the study from the Headaches Centre of the Neurological Institute C. Besta in Milan for routine visits (Table 1). Inclusion criteria were: age 11 - 17; diagnosis of (episodic or chronic) migraine with or without aura; tension-type headache. Exclusion criteria: patients unable to give their consent or with insufficient comprehension of the Italian language; patients whose parents/legal guardians refused to give the consent; absence of other chronic illness or developmental delay were excluded. Recruitment continued until thematic saturation was achieved or until no new themes emerged from interviews: we defined saturation as the point at which, for 3 consecutive interviews, no new themes emerged. At the end of the neurological medical examination, the neurologist (LG) presented the research aims and engaged parents/legal guardian and $\mathrm{PPwH}$ in research interviewing. All patients were invited to participate in one narrative interview with 1 psychologist (VC, PhD, female) with 10 years of experience in qualitative research methodology. Patients and interviewers had no prior relationship or knowledge.

\subsection{Narrative Interview}

We performed in-depth narrative interviews, following a semi-structured 
Table 1. Sociodemographic characteristics.

\begin{tabular}{|c|c|c|c|c|c|c|c|c|c|c|}
\hline Patients ID & Age & Gender & Education & $\begin{array}{c}\text { Sports } \\
\text { activities }\end{array}$ & $\begin{array}{l}\text { Headache } \\
\text { frequency } \\
\text { and features }\end{array}$ & $\begin{array}{l}\text { Age at } \\
\text { Onset }\end{array}$ & Familiarity & $\begin{array}{l}\text { Prescribed } \\
\text { Prophylaxis }\end{array}$ & $\begin{array}{l}\text { Interview } \\
\text { length } \\
\text { (min.) }\end{array}$ & $\begin{array}{l}\text { Words } \\
\text { count }\end{array}$ \\
\hline $01-\mathrm{F}-17$ & 17 & $\mathrm{~F}$ & HS & no & $\begin{array}{c}\text { 10/month TTH; } \\
\text { MwoA }\end{array}$ & 7 & no & TFS & 16.55 & 1151 \\
\hline $02-\mathrm{F}-12$ & 12 & $\mathrm{~F}$ & MS & yes & 3/month MwoA & 6 & no & Pizotifen & 13.56 & 759 \\
\hline 03-F-15 & 15 & $\mathrm{~F}$ & HS & yes & 2/month MwoA & 7 & yes & - & 15.50 & 1191 \\
\hline 04-F-17 & 17 & F & HS & yes & $1 /$ month MwoA & 10 & no & - & 17.29 & 1292 \\
\hline 05-F-14 & 14 & F & MS & yes & 3/month MwoA & 7 & no & - & 20.18 & 1967 \\
\hline 06-M-12 & 12 & M & MS & no & $\begin{array}{c}\text { 2/month TTH; } \\
\text { MwoA }\end{array}$ & 5 & yes & TFS & 11.53 & 870 \\
\hline $07-F-16$ & 14 & F & HS & yes & 4/month MwoA & 11 & no & TFS & 11.52 & 993 \\
\hline 08-F-15 & 15 & F & HS & no & $\begin{array}{c}\text { 28/month TTH; } \\
\text { MwoA }\end{array}$ & 13 & no & TFS & 15.11 & 1104 \\
\hline 09-M-15 & 15 & M & HS & yes & 4/month MwoA & 12 & no & TFS & 9.09 & 709 \\
\hline $10-\mathrm{M}-14$ & 14 & M & HS & yes & $\begin{array}{c}\text { 5/month TTH; } \\
\text { MwoA }\end{array}$ & 6 & yes & - & 22.2 & 1952 \\
\hline $11-\mathrm{M}-14$ & 14 & M & HS & no & $\begin{array}{c}\text { 28/month TTH; } \\
\text { MwoA }\end{array}$ & 8 & no & TFS; & 31.3 & 199 \\
\hline $12-\mathrm{F}-17$ & 17 & F & HS & yes & 20/month TTH & 16 & no & TFS & 26.5 & 1540 \\
\hline 13-M-13 & 13 & M & MS & yes & 8/month MwoA & 6 & no & TFS & 23.27 & 1164 \\
\hline 14-M-12 & 12 & M & MS & Yes & 8/month TTH & 11 & yes & TFS & 27.04 & 1515 \\
\hline $15-F-17$ & 17 & F & HS & Yes & $\begin{array}{c}\text { 12/month TTH; } \\
\text { MwoA }\end{array}$ & 6 & no & TFS & 17.01 & 1254 \\
\hline $16-F-14$ & 14 & $\mathrm{~F}$ & HS & Yes & 8/month MwoA & 5 & yes & TFS & 17.07 & 1099 \\
\hline 17-F-18 & 17 & F & HS & Yes & $\begin{array}{c}\text { 20/month TTH; } \\
\text { MwoA }\end{array}$ & 8 & yes & TFS & 28.17 & 2594 \\
\hline $18-\mathrm{M}-15$ & 15 & M & HS & Yes & 12/month TTH & 10 & no & TFS & 15.55 & 675 \\
\hline 19-F-17 & 17 & F & HS & No & $\begin{array}{c}\text { 20/month TTH; } \\
\text { MwoA }\end{array}$ & 10 & no & TFS & 18.53 & 1092 \\
\hline $20-F-12$ & 12 & F & MS & Yes & 2/month MwA & 10 & yes & TFS & 23.14 & 1627 \\
\hline 21-F-17 & 17 & F & HS & Yes & $\begin{array}{c}\text { 20/month TTH; } \\
\text { MwoA }\end{array}$ & 6 & yes & TFS; Antidepressant & 16.38 & 467 \\
\hline $22-\mathrm{M}-13$ & 13 & M & MS & Yes & $1 /$ month MwoA & 11 & yes & TFS & 19.56 & 1129 \\
\hline 23-M-11 & 11 & M & MS & Yes & 4/month MwoA & 10,5 & yes & TFS & 12.52 & 784 \\
\hline Group comparison & Age & NA & $\begin{array}{l}\% \text { high } \\
\text { school }\end{array}$ & NA & $\begin{array}{l}\text { Headache } \\
\text { frequency }\end{array}$ & $\begin{array}{l}\text { Age at } \\
\text { Onset }\end{array}$ & $\%$ yes & NA & $\begin{array}{l}\text { Length } \\
\text { (minutes) }\end{array}$ & $\begin{array}{l}\text { Words } \\
\text { count }\end{array}$ \\
\hline Female & 15.4 & - & 78.6 & - & $12.0 \pm 8.3$ & $10.04 \pm 1.5$ & $55.6 \%$ & - & 18.3 & 1115.1 \\
\hline Male & 13.2 & - & 44.4 & - & $6.3 \pm 8.5$ & $6.78 \pm 2.8$ & $35.7 \%$ & - & 19.1 & 1220.8 \\
\hline$P$ value & 0.01 & - & 0.30 & - & 0.057 & 0.005 & 0.30 & - & 0.85 & 0.70 \\
\hline
\end{tabular}

M, male; F, female; HS, high school; MS, middle school; Mo, mother; Fa, father; Si, sister; Br, Brother; MwoA, migraine without aura; MwA, migraine with aura; TTH, tension-type headache; TFS, Therapeutic Food Supplements; NSAIDs, non-steroidal anti-inflammatory drugs; Continuous variables are expressed as means \pm standard deviations and $P$ value is referred to Mann-Whitney $\mathrm{U}$ test. Categorical variables are expressed as percentages and $P$ value is referred to chi-squared test. 
protocol guide set out in advance (Table 2), taking care of established climate that allows for storytelling in all its forms [26]. Interviews were conducted in a private room of the hospital and began with a general statement inviting patients to narrate their experience with headache: "How would you describe your experience with your health condition? You can start wherever you prefer and tell me whatever you think is important" [27]. Then, the interviewer proposed additional stimuli to help participants examine in depth their answers and their descriptions of the experience lived ("what happened next?"). Following the flow of the story the interviewer tried to deepen the three dimensions of patient experience described by Kleinmann [28] (disease, illness and sickness) [29]. The interview guide also provided for the collection of sociodemographic data (age, family composition, sports or recreational activities carried out). Additional information about patients' health condition was retrieved from the medical record.

\subsection{Data Analysis}

Descriptive statistics (i.e., frequencies, percentages, means, and standard deviations) were performed to describe the socio-demographic characteristics and medical data of participants involved in the study (Table 1). All interviews were transcribed verbatim and then analysed following a 1) narrative analysis and a 2) thematic analysis. Then, 3) a composite first-person narrative was developed.

Following Riessman [30], the entire response of the interviewee was considered as a personal narrative with an intrinsic coherence: the narrative's meaningfulness is guaranteed by the researcher's interest in the illness experience of

Table 2. Interview guide for collection of patients' narratives.

\section{General statement/Illness dimension}

- Can you tell us your experience with headache?

- What's headache to you? How do you call it?

Disease and temporal dimension

- Tell me about the path to the diagnosis (appearance of symptoms, examinations, etc.).

\section{Sickness dimension}

- How much does headache impact on your everyday life? (at school, with your family or peers, at sports or leisure activities)

- How headache is perceived or defined by other people? What do other people think about headaches?

Causality and impact on your life

- What causes you to have a headache?

- Had to give something up because of the headache?

\section{Future}

- Thinking about the future, do you think your headache will continue?

\section{Final remarks}

Finally, we leave you another space in which you can write other comments, ideas or impressions aroused by these themes. 
PPwH. Embedded in this personal narrative there could be "minimal narratives" [31] - the narration of past events in temporal order-and narrations of ongoing states of being, narrations of present, future or hypothetical experience and also non-narrative segment. Moreover, in personal narratives different topics and themes can be explored, maintaining a substantial coherence conveyed by the telling-by narrator's voice and point of view_rather than by the told as a plot. As sociologist Arthur Frank [32] argued, illness narratives can sometimes be chaotic, lacking narrative order, plot or well defined causal links between events, while still having a distinctive voice: "Yet if the chaotic story cannot be told, the voice of chaos can be identified and a story reconstructed". We consider personal narratives because through interpretation they can reveal truths about narrators' experiences, how they construct the meaning of the experiences (or try to), and how they want to be understood.

\section{1) Close Reading and Narrative Analysis}

Firstly, each transcript was close read to engage with the data. Close reading is a method derived from the literary critic, proposed by Rita Charon [33] as a mean to improve the understanding of patient's stories in health professional education. We applied the same attention to the text as method in our narrative analysis [34], with the same ethical stance: thinking with stories [32], bearing witness and honoring them [35].

We read the stories several times: specific features as time, space, voice, metaphor, genre, structure of language as well as personal response to the texts were annotated. Then narratives were read again, searching for specific structure features. Narrative segments were pinpointed, and those corresponding to Labov's description of minimal narrative-containing "a sequence of two clauses which are temporally ordered" [31] —-were analysed discerning the kind of narrative clause that includes abstract, orientation, complicating action, evaluation, resolution, and coda [36] [37]. Then we came back to consider every narrative as a whole: as in holistic approaches to narrative analysis [38] we emphasize that meaning must be derived for a contextual reading of the data, by the mean of an interpretative act. We try to answer the question "What is the point of telling this kind of story?" Then the annotations from close reading and those from structural analysis there compared to this core meaning. Finally, we identify two typology reflecting people's narrative resources [26]. Two researchers (VC, FM) have carried out these steps in parallel, achieving sufficient familiarity with the materials to be able validly to interpret them. They continually have confronted each other on the emotions that arose by the reading, on personal memories emerged, and they have checked their evolving interpretations. Moreover, they have shared reflection about the ethical dimension involved in reading and in being involved in the interpretation of patients' stories.

\section{2) Thematic Analysis}


According to the method of qualitative analysis of content [39] a thematic analysis was performed on qualitative data. The thematic analysis followed the six phases identified and described by Braun and Clarke [40]. Then, researcher reading and re-reading the data so as to be deeply familiar with the breadth of the content; in the second phase, an initial list of codes was generated by applying codes to segments of interviews. Coding was performed manually. Thirdly, all identified codes were collected into potential themes and in the next phase all themes and subthemes were organized in a visual paper-based representation. The fifth stage was served to redefine and refine the themes identified and clearly defined the final themes configuration, presented here as a final phase of production report. The thematic analysis was performed independently by two researchers, a neurologist physician and a psychologist (LG; VC); disagreements have been resolved through the discussion.

Themes within data were identified according to a theoretical or deductive way [40]. According to Hsieh and Shannon [41] we follow a directed analysis of content approach, in which initial coding started in coherence with disease/illness/sickness classification [28] and then news themes emerge from the data in order to extend the initial conceptual framework. "Illness" refers to the illness with which the person identifies himself or herself on the basis of his or her own perceptions and experiences of the symptoms experienced. Patients report health problems, more or less serious, which may limit their ability to lead a normal life. "Disease" refers to a condition that is diagnosed by a physician. Patients report the specific condition from a biomedical point of view, its causes, treatment and care. "Sickness" refers to the social role that a sick person plays or is played in society in different areas of life (e.g. absences from work due to illness or, in the case of adolescents, absences from school or sports activities). These data are used to measure the social consequences of the person with a certain illness.

\section{3) Paradigmatic First-Person Narrative}

As final step of the analysis, the researchers (VC, LG, FM) co-construct a narrative that emerged from the analysis and from personal response to reading.

In Narrative Medicine practice the health professional is invited to write down the story he has listened to: this process is intended to represent what he or she has witnessed, making it newly visible to both the listener and the teller [23]. Also in Narrative Inquiry is a well-known tradition to create a first person narrative. Clandinin and Connely [42] describe emplotment, as "the amalgamation of multiple interviews/conversations into one narrative that encompasses the events discussed, presented in a sequence that creates a narrative plot”. Polkinghorne [43] claims that the research product of narrative analysis is a story-a case, a biography, a life history, an autobiography, an autoethnography-that is composed by the researcher to represent the events, characters, and issues that he or she has studied. Ely [44] advocates for "more attention to the power of first-person stories both for giving voice-to our participant as well as 
to ourselves-and for breaching as best we can the We/Other divide with its elitist noncollaborative messages". Considering research as a hermeneutical practice, researchers have followed the "composite first person narrative", described in phenomenological research, by Todres [45]. The composite first person narrative is a mean to "create new understandings of the phenomenon, bringing about a form of understanding that is relationally alive that contributes to improved caring practices" Wertz [46]. The same researchers who were familiar with the narratives collected were involved in the generating process of the final version of the first-person narrative, creating an evocative, but not exhaustive, story of the complex experience of PPWH, an empathetic account of the insights gleaned through the research.

\section{Results}

A total of 23 patients between the ages of 12 and 17 were involved. Among them, 14 females $(60.9 \%)$ and 9 males (39.1\%), with an average age of 14.5 years (min-max 12 - 17) (Table 1). The interviews lasted an average of 19 minutes (min 9-max 31). All patients live with their parents and siblings (3 are only children) and, with the exception of three, they all play sports or physical activity in their free time (gym, football, volleyball, basketball, riding, swim).

On average, participants have been suffering from headache or migraine for 5.8 years (s.d.3.3) and the age of onset is 8.8 years old (s.d.2.9). Diagnosis: 9 migraine without aura, 8 tension-type headache \& migraine without aura, 3 tension-type headache, 2 tension-type headache \& migraine without aura, $1 \mathrm{mi}$ graine with aura. Ten patients report the presence of people suffering from migraine or headache in their families: half mention female relatives (mothers, grandmothers or aunts) and the other half mention male relatives (father, grandfather, brother).

Results related to the 1) narrative analysis, 2) thematic analysis, and 3) the first-person narrative were presented as follows.

\section{1) Close reading and narrative analysis}

\subsection{Memories of Meaningful Events}

Most of the narratives of PPWH have a temporal structure built from habitual or recurrent events. Even on specific request to tell the onset or a meaningful episode, some participants address the continuing living-through the experience of headache:

Prompt. Can you tell me your experience with headache?

Reply. I ve been having it since I was little, that is to say, I started having it, even in elementary school, many times I had a lot of headaches and... I used to have breakfast in the morning, but now I don't have it anymore and that's why everyone yells at me, anyway nothing, $P$ ve been having it since I was little... (P3-F-15) 
Spontaneous narrations of specific events in the past are about the onset, the memory of the first time, or the first memory of a headache experience. Rarely there is the memory of a headache-free first or is vague and confusing.

I remember the first time, I don't remember if I was in first or second year [into first-grade secondary school-authors note], I came home from school and I was eating and I remember watching $T V$ and I started seeing everything a little bit blurry. At first I didn't notice it, I thought I must be a bit tired and then I started to see that it was bothering me so much. Even then when I went to the ER I had to say that I was watching TV, I couldn't say the word TV, but I was aware that I couldn't say it, I was saying that place where you watch cartoons, and yes I got a little scared because I didn't know what it was. And then they gave me something and then I fell asleep and it passed. (P7-F-16)

Other narrative segments are about situations addressed by the interview questions: situations of incomprehension, particularly serious episodes, withdrawal caused by the headache. Others are about meaningful places where the narrator lives his experience: school, gym, and places frequented during leisure time (the city, disco, bar).

The CODA clause, returning to the now of the telling, is often the same through different narratives: in the present the headache is under control, normal, a habit or simple to be accepted:

- Well, it's getting better now. (P1-F-17)

- Nowadays, if it hurts me every day I don't pay much attention because it's a habit now. (P8-F-15)

- But P ve always been able to do everything normally. (P17-F-18)

Event narrative segments can perform different functions within the general narrative: often retracing the sequence of events becomes a way to build a theory about headache causes ("In fact, now that I think about it, the headache came to me more after they found me a... how do you say, an earache." P4-F-17). For example, in interview P12-F-17, the narrator, in retracing the events, compares different evaluations - that of the parents, or that of the doctors-presented as voices within his narrative to affirm his personal theory, at the end.

So, let's say that in particular in this last school year, I started in the fourth grade $\mathrm{Im}$ in Human Sciences High School, last year I was in third grade, and let's say that I tend to stress so much for the school tests, even though I $m$ doing well and I have good grades, let's say that I tend to stress too much because I $m$ afraid maybe of the result, of not doing well, of not making it and during the whole year I had this stress and I started to have pain in my temples fixed.

My parents thought it was due to my eyesight because I have my short-sightedness, let's say I always get worse. I made some visits and initially it was because of this but it's not that I always get worse so we understood that it wasn't because of my eyesight. Then they found me with celiac disease about 2 3 years ago and they thought it was because of the low iron then it stabilized even if it is now lowered again. During the summer headache was relieved be- 
cause I didn't have school stress. But if it was due to the school stress it should have gone away completely during the summer, instead it hasn't gone away at all, it's just improved, but now that I started school it's back as before.

The theme of commitment and school stress returns several times in this narrative, as a more general evaluation of life choices and personal abilities. The narration of events, in fact, is also used to present one's own identity:

I open a parenthesis, I have 10 books waiting for me from this summer, because having had the exams I read little, maybe because I went up to bed and I was so tired that I could not take the book, I was so sorry not to take the book and now I do not have homework for these holidays, I have 10 books waiting for me. I tried to read a 350-page book in 13 hours... (P5-F-14)

\subsection{Narrations of Habits and Recurrent Situations}

Often, the narrative segments of recurrent events or habit are told with a typical language and feature: vivid present, temporal adverbs (usually, typically) symmetrical, hypothetical and temporal structures (when/when, if/then, maybe this, maybe that, sometimes/other times, it happens).

At first I only hurt my eye and nostril, then my eye, then my nostril, then my teeth, but now my eye, nostril, teeth, ear, and sometimes this part of my head... Sometimes I get it when I wake up and if it's strong I take "Tachipirina” even if it doesn't do much, while sometimes I get it when I'm not doing anything. Practically if I have it I have to wait for the night so I sleep and then it goes away even if I take the "Tachipirina" (paracetamol), instead other times it goes away so suddenly... (P14-M-12)

Recurrent situations are also recurrent emotional state following the headache trend or relational situations:

If I have a strong headache it affects me a lot because I get sour like an expired yogurt, because I $m$ really angry, you don't have to touch me, you don't have to talk to me, no leave me alone then I have a friend in particular who talks, talks, talks, talks and even if you tell her "P $\mathrm{m}$ sick" she keeps on talking and so I hate her when she does this. (P1-F-17)

Or chronicle of daily routine:

In the morning I wake up quite early around 6:30 a.m., then I have breakfast at school and I let my dad drive me in the car in the morning, then at school I do 6 hours and before that I did Sport (...). First I used to go straight after school then I would come home and have lunch, now I'm not doing anything sport after school so I come home for lunch, then I study, then of course I can't always study straight after school, sometimes I'm tired, so I rest and study later (P12-F-17)

Narrations of this kind can also be found to describe other aspects of life, not strictly relevant to headache, for example, a participant explains her method of study in this way:

I have a method of study, usually I study with maps, so maybe it takes me a 
long time, if I do 100 pages, maybe I divide the things to do, but I can't always do it because maybe it's not the only subject I have to study, so in the end I find myself with 50 pages to study and make maps, so it means taking the book, reading, studying the important things, rewriting it, it's a long process to do... (P5-F-14)

Recurrent narratives sometimes help to formulate theories about causes, similar to scientific theories, based on the observation of occurrence, identification of recurrences and variants, that allow formulating useful hypotheses as predictive models and operational strategies. They are answers to the question "how does my headache work?".

I already know that this week is going to happen to me because it s going to be full of trials and so I can understand. (P3-F-15)

And usually I get a headache pretty early, I also wake up around 5:00 a.m. and have a headache so when I do, it's not a passing headache but something more serious, so on that day maybe I don't go to school... (P22-M-13)

Sometimes the operational script is simply to accept to be at the mercy of the headache trend, because there is no rule, except that it will go away.

because I do all the sports all the time. Even if it comes later, I do it because I like it. Even running, I m going to have the races soon, but I do them, they come to me and then they go away... (P20-F-12)

Talking about recurrent events, sometimes, can be significant for the narrator's story of "who I am", with the attribution of personal meaning to the experience, a motivation integrated into the life story, or correlated with narrative identity.

Interviewer. I understand that many episodes that happen to you are related to physical activity.

Reply: yes, but... I never get them in swimming, I never get them in gymnastics. Only when I get too tired. During training the teacher makes us do things of our level but not too much. When $1 \mathrm{~m}$ on my own I challenge myself to do things, I never stop, because I always want to be able to do things, to do an element and so they come to me. If I don't get tired, no... (P20-F-12)

\subsection{Autobiography and Direction for Use}

Following this feature, PPWH narratives were classified through a continuum between two extremes: 1) Outnumbering events narratives; 2) Outnumbering habitual narratives. As the event narrative segments prevail-not only in quantitative terms but also in terms of symbolic weight-the whole narrative seems to get closer to an autobiography or a formative novel (bildungromans). We have chosen as a title for this genre "The story I tell, the story I am". The participant P17-F-18 is an example: the narrator tells step-by-step the pathway to find a diagnosis and a treatment, describing different antagonists and troubles. The narrator creates a climax of unfolding events in which the protagonist is carried passively and her voice finds no space or credibility; the narration is resolved in 
a claim of agency (and I said no) and in the choice of a personal stance in the world. (Last year was the most difficult year, in fact, it affected the school, $1 \mathrm{~m}$ sorry because $P$ ve always been good enough but I prefer to care about my health).

As the habitual narrative segments prevail, the whole narrative seems to get closer to a kind of operative/predictive algorithm: we have chosen as a title for this genre "My Life: directions for use". For Example in interview 20F-12 brief event narrative segments are used as examples which confirm the rule or exception, to show when the rule (or a set of rules) works o doesn't work and how to act in every situation. The narrator describes himself as an expert and in control and his experience as another manageable routine. He transmits the sense of agency also during situations of tolerable uncertainty.

Between those extremes there are narratives "in search of..." sometimes of a personal meaning, sometimes of a rule (or a set of rules) that makes manageable different recurrent situations, often of a mix of both.

\section{2) Thematic Analysis}

The thematic analysis allows us to identify 5 themes end 22 subthemes. The results of the thematic analysis are summarised in Table 3. Each theme is described below.

Disease. Most of the interviewees, especially in the first part of each narrative when asked to tell their experience with headache, focus their attention on the physiological aspects of the disease, describing particularly the pain and which parts of the head are affected by the pain. They then go on to tell how long they have been suffering from headache. All those interviewed know how to locate headache and the symptoms associated with it (vomiting, nausea, discomfort with noise and odours, tiredness, etc.). Few of them refer to medical examinations made over the years or mention the diagnosis. Finally, most of participants take medication when the pain is too severe, but it does not always work.

Illness. According to participants, headache has become a familiar experience, it's become a habit. Headache also affects patients' personal characteristics. Pain transforms and changes them, it makes them more annoying, irritable ("pain really makes me change"). Headache is cause of anger in participants, related to annoyance or noise caused by other people. About anger, one interviewee intriguingly points out that headache makes her angry because they don't all have it, and this bothered her especially when she was a kid. Another subtheme refers to the knowledge and understanding of their state of health. Respondents recognise the symptoms associated with headache but they don't know how to fix it.

Sickness. This theme is related to the social role that a sick person plays or is played in society in different areas of life (e.g. family, school, hobbies or sports activities). Overall, respondents feel understood by their parents, who give them comfort and advice on how to deal with pain. If siblings are not too young to bother them, understand their health condition also. At school, respondents say 
Table 3. Themes and subthemes identified from patients' narratives.

\begin{tabular}{lll}
\hline Theme & Subtheme Examples of patients quotations
\end{tabular}

Disease dimension

1) Description of pain

2) Medication: I know what to take

3) Drugs: not always work

4) Medical Examination

Illness dimension

5) It's a habit

6) "It transforms me, I become intractable"

7) Headache makes me angry

8) Understanding of headache: There's something I'm missing.

9) Understanding of headache: I don't know how to fix it

Sickness dimension
- $\quad$ I ve been seeing it almost every day for a year now and it's always almost strong enough because it takes the temple or the back of the head. P8-F-15

- It started a year ago, a year and a half ago, at the beginning only my eye and nostril hurt, then my eye, nostril my teeth, but now my eye, nostril, teeth, ear and sometimes this part of my head hurt. P14-M-12

- I always take "Tachipirina" because the doctors told me to, and mine too. P7-F-16

- I take the drugs my mother tells me. If it's strong but not too "OKP'. If it's very strong "Tachipirina”. P18 M-15

- If it's strong I take “Tachipirina” even if it doesn't do me much, while sometimes I get it when I $m$ not doing anything. P14-M-12

- We changed a lot of drugs, at first I was taking "Tachipirina", then "Moment", "Nurofen", although sometimes it doesn't go away. P13-M-13

- I ve had this headache since I was a little girl, in fact since I was little I had to go to the doctor for the headache even if in the end they said it was nothing much, then as time went by it got worse and in the end only this one. P19-F-17

- $\quad$ Then in junior high school it started to get worse but I always managed to do everything normally, it was more attacks that I had, the doctor had said migraine attacks and I started going to an osteopath. Then they made me do tests for diabetes and celiac disease because my mum's brothers suffer from diabetes and coeliac disease and they started suffering from migraine too. $P 17-F-18$

- I thought it was a common headache like everyone else, I didn't pay much attention to it and even though it hurts every day now I don't pay much attention to it because it's a habit now. P8-F-15

- Then another time it was the only time when I woke up it didn't pass me and I had to stay in the hospital, but now I got used to it. P7-F-16

- If I have a strong headache, it's very influential because I get sour like an expired yogurt, because I m really angry, you don't have to touch me, you don't have to talk to me, no leave me alone. $P 1-F-17$

- When I have a headache, anything that bothers me becomes unbearable, everything they tell me I react badly, I respond badly because the pain really makes me change. P13-M-13

- $\quad$ Sometimes, maybe because of the headache 19 more sensitive, maybe when they tell me something that bothers me I get a little angry. P8-F-15

- Sometimes I get a headache and it's a bad day, or at least when I have a headache and I have people around me who mess up I get angry. P5-F-14

- I think I know enough then actually I always think there's something I m missing, like all these tests on the cycle or liver. P17-F-18

- I know what I have, but there's something I m missing. P18 M-15

- I know what I have but I can't figure out how to fix it. P10-M-14

- Sometimes I live in a situation that I don't understand much, I feel like I m going to throw up but I can't and I don't know what to do. P22-M-13

- $\quad$ Mom understands it because sometimes she gets headaches too, daddy tells me to stay there quiet, sometimes when I go to tell him it hurts really badly he tells me he can't do anything about it, then my brothers help me, they tell me: "try to lie down, try to be quiet", they give me some advice". P6-M-12

- $\quad$ [ When headache] was really strong, I took the medicine and went to bed. Then my mom usually uses either cold water on my head or gets a little relief from the very strong massage on my forehead and so many times I fall asleep. P13-M-13 
11) Family members: siblings don't always understand

12) At school: teachers who suffer from headaches understand me

13) Friends: they understand who suffers from headaches

14) Headache perceived by other people: understimate

15) Impact on social activities Missed experiences: I don't go out in pain/I go out anyway, grit my teeth...

16) School-related stress

17) Emotional stress I get angry and I get a headache.

18) Physical stress

19) Physical aetiology
Even my brother, even if we get along well, breaks a lot [...] many times we are quiet in bed, he comes and pulls the pillows, very often they bother me. P19-F-17

- When I m not well, [the headache makes me sick] as if I had a fever, yes, [my sister] understands me and she is kind. When headache is normal she doesn't understand it, she increases it there. $P 10-M-14$

- Teachers at school don't understand anything, zero: "What are you doing, you have a headache only, where are you going?" I said: "P m going home because I have a headache". And Teacher. "What does it mean to go home because you have a headache?" P1-F-17

- At school I have two teachers who also suffer from headaches so one of them always tells me that when they get headaches, they tell me that they see everything blurred or dark moments. P4-F-17

- It happened with some classmates of mine, they joke about it, that is they are my friends but sometimes they joke about it. P4-F-17

- $\quad$ A friend of mine [also suffers from headache] and she also takes "Tachipirina" but we don't often talk about what we feel when we have headaches. When she has pain, she stays with me and I tell her a lot and then it goes away, it's nothing serious. P20-F-12

- In my opinion those who don't have headache can't understand, maybe they associate headache with a cold, many don't understand it. P15-F-17

- I don't think it's such an important thing to tell the teachers, then maybe they underestimate it by saying "Yes but you have a headache" so I don't tell them mainly because of that. P12-F-17

- For example [when I go] to the disco with my friends, I don't go there if I have a headache, I did it once and then I got sick, that's it. P4-F-17

- [it happened] rarely that I didn't go out at all, because I like to go out anyway, so despite the pain, $I d$ rather mix medicine first. If we go to bars or dance, I go dancing with a headache. $P 1-F-17$

- Very often due to a drop in tension after a stressful period, for example if I study a lot. Also last year, just after the Christmas holidays in January, I studied a lot for a lot of tests and in fact the week after every day I was sick, not so much, I used to get a lot one day, after training sometimes, and more or less enough, when I have my cycle. P3-F-15 - Let's say that I tend to stress myself so much for questions even though I do well and have good grades, let's say that I tend to stress myself too much because I am afraid of the result, of not doing well, of not making it. P12-F-17

- If I know it's not going to go well no [the test at school], if I know it's going well and then it's not going well, when I get home I get very angry and I get a headache. $P 10-M-14$

- I get angry and I get a headache. P23-M-11

- On training days [basket] it comes to me more or less towards the end because I make a lot of effort and it's more likely to come to me. P13-M-13

- An episode when I was playing good volleyball I got this headache I couldn't play and I got angry. P16-F-14

- My parents thought it was because of my eyesight, because of my near-sightedness $1 \mathrm{~m}$ kind of getting worse all the time. I made some visits and initially it was because of this but it 's not that I always get worse so we understood that it wasn't because of my eyesight. P12-F-17

- The headache, I remember, came mostly after they found me a... how do you say, an earache, which was piercing my eardrum, after that time there they discovered my headache. P4-F-17 


\begin{tabular}{|c|c|c|}
\hline Coping & $\begin{array}{l}\text { 20) They know how to cope } \\
\text { with }\end{array}$ & $\begin{array}{l}\text { When I suffer from severe headaches I don't want anything I don't want the TV on, if I } \\
\text { stand in front of the phone I don't hear anything, it's the only thing that distracts me. } \\
P 10-M-14 \\
\text { - } \\
\text { [headache attacks] started in primary school, but anyway, it's not that I get them very } \\
\text { often, but when I get them I know how to do it [...] well, when I think about headaches } \\
\text { I think I should rest a little bit. P5-F-14 }\end{array}$ \\
\hline \multirow[t]{2}{*}{$\begin{array}{l}\text { Future } \\
\text { perception }\end{array}$} & $\begin{array}{l}\text { 21) It will last for quite a } \\
\text { while/forever. }\end{array}$ & $\begin{array}{l}\text { - I ve had it since I was little, I hope it's very short but I think it will be one thing... also } \\
\text { because my family, my aunt... has always had it P3-F-15. } \\
\text { - My doctors have said my whole life, but they told me I might have periods when I } \\
\text { might not have it for } 5 \text { to } 10 \text { years and then it might come back, so I don't know. I hope } \\
\text { that when I } m \text { a little older it will end. P17-F-18 }\end{array}$ \\
\hline & 22) I hope it will be better & $\begin{array}{l}\text { - Well, I hope it gets better, honestly, because I don't want to have it for the rest of my } \\
\text { life. P1-F-17 } \\
\text { - } \quad \text { I hope it passes, maybe it decreases with time, maybe it stays but it decreases. P7-F-16 }\end{array}$ \\
\hline
\end{tabular}

Note: patients ID in brackets referred to gender and age (e.g. P1-F17: this is the patient number 1, female, 17 years old).

they are not always understood. It is mainly teachers who also suffer from headaches who show more understanding. The same goes for friends, those who already suffer from headache are more sympathetic, unlike those who do not know what it feels like to have headache, "they laugh it off". Generally speaking, respondents believe that people do not fully understand their pain and what they are experiencing ("how do you think others consider headaches?") and they believe that people tend to "underestimate" their pain ("it's just a headache").

Causality. Almost all refer to school performance-related stress and how headaches are linked to more stressful times at school. Participants also identify anger as the cause of the headache ("when I get angry, then I get a headache"), physical stress (after sporting activity) or physical aetiology (e.g. visual impairment, otitis).

Coping. The theme is related to how participants cope with the pain. Participants are "expert" patients, they know what they do when the pain is too severe ("when the headaches come, I know how to do it") or received advises by family members on how to deal with it. Most of the "remedies" refer to rest, isolation and only when the pain is unbearable they resort to medication.

Future. The sample is twofold divided: those who think that the "headache" will last over time, or forever, and it is mainly those who have a familiarity or complain of pain associated with a certain physical state (for example, in the case of girls on their menstrual cycle), and those who hope headache will improve over time, and it is mainly those who attribute the pain to stress and school. Only two respondents replied that they had never thought about what their state of health would be like in the future.

\section{3) Paradigmatic first-person narrative}

As explained in the method section, the narrative below has been constructed following the structural and thematic analysis carried out on the interviews. 
" $P$ ve been having these strong headaches for a few years, since primary school, and they've increased since I started middle school, and now in high school it s sometimes like having a hammer inside my brain. But not always, it depends on the periods, and by now $P \mathrm{~m}$ used to it, even if something escapes me, I don't understand. The first times I was scared, I didn't understand, other times I get angry because I have it so strong, but now I know what to do. Now, P ve learned that if everyone leaves me alone, in silence, I lie down on bed and slowly it gets better. That's it, when the pain is very, very strong I get annoyed by all the noises and I need to isolate myself. Usually I prefer not to take anything, but if it really doesn't pass then I take a painkiller. That's what the doctor told me to do, she told me what to take and then I always ask my mom too. Then $P$ ve seen it get worse when I have some tests at school. I think it's either because P $m$ anxious or I get tired at other times. For example, now there will be the final tests and I know headaches will increase. That's just the way I am, I really want to do well in school. And also in sports. I ve been swimming for 5 years and 1 ve been competing for 2 years. Headaches happen especially during swimming competitions, or at the end of very intense training. Usually if my mother sees that I feel bad she'll leave me alone, she closes the door and turns off the light: she often has a headache and she understands what it is like. On the other hand, my younger brother complicates everything. Every time I try to concentrate on studying, here he comes. Sometimes I tell him not to make too much noise and instead he does it louder. I get along with my girlfriends, especially swimming mates. They tell me that sometimes they have headaches too, but not like that and when I feel bad they try to help me. Once I had to go out with them to go to a party, I tried to resist as much as I could, but then I felt like throwing up. So my best friend called my parents and they came to pick me up. Now, if I have to go out, I take my meds with me, but if $1 \mathrm{~m}$ feeling really bad, I go back home. Teachers at school don't always understand. The English teacher made me really angry. She kept repeating to me "it's just a headache, come on, come on" and the more she said it the more I felt bad and angry. I think if you don't go through it you can't really understand. My school-mates understood that they have to leave me alone because if I have pain I become intractable, and sometimes the pain passes by itself. If I think about the future I think I will always have it, like my mother and my aunt, but I want to be confident'.

\section{Discussion}

To our knowledge, this is the first study to explore the illness perceptions of 23 $\mathrm{PPwH}$ by a narrative medicine approach and narrative research method. The three types of analysis carried out on the interviews allowed us to describe interesting findings that might help clinicians to better understand and respond to the particular needs and concerns of this patient population: narrative analysis of collected interviews revealed different ways to organize the illness experience; thematic analysis identified 5 main themes and 22 subthemes about the signi- 
ficance of being a $\mathrm{PPwH}$ and the construction of the prototypic story provided a mean that neurologists could use with these types of patients in clinical practice.

Narrative analysis of patients' illness stories revealed different ways to organize the experience of the health condition. In narrative research about health or trauma, typically, illness narratives were framed in the context of a "biographic disruption" [47]. In our study, few PPWH describe a biographic disruption, a time before and a time after the illness occurred, as happens in narratives of adult patients with headache [48] or in patients with other health conditions [49] and their caregivers [50]. This could be related to a very early age of onset, about 9 years: few of them talk about a biographic disruption if the headache onset is still near, whereas most patients have a vague memory of when the disease started. Rather, it is perhaps more appropriate to talk about a "biographical continuity", as pointed out by Levelahti and colleagues [49]. This continuity is expressed by referring to, for example, the familiarity of the disease, to events related to their growth (change of school or sports activities) and/or to bodily changes.

Moreover, as results both from narrative and thematic analysis, it is remarkable that for some participants is not necessary to find an existential meaning of the illness experience, it is more important to find a way to manage headaches in daily living. A self-exploration, a reflection about narrative identity integrating illness is more frequent in older participants, the younger prefer a kind of life exploration, to find agency through action than through meaning construction. Literature shows the key role of conversational storytelling in late adolescence and early adulthood for narrative identity development. McAdams and McLean [51] emphasize the benefits of narrative identity for psychological well-being and maturity, and the importance of promoting self-exploration through conversation (possibly even among peers). Conversational storytelling affects the development of narrative identity in late adolescence and early adulthood and narration can be important when a disease is present in a teenager's life by giving a meaning to their experience [52]. In fact, considering the thematic analysis, a relevant aspect that emerged is the impact of headache on the way they perceive and define themselves. Headache is something that changes and transforms them, when the pain is present they feel like another person and it is also something that makes them angry. Narration could be suggested, for example through the use of a diary in clinical practice, not only to write when attacks [53] occur but also in general about their experience.

Another relevant feature is the scarcity of the disease dimension (i.e. the pathway of care, the diagnosis, and the drugs). Also, the symptoms are described not from a medical standpoint, but from the within of the lived experience of pain. The medical gaze rarely enters into the participant narratives, the body dimension is explored as Leib, the lived-living body as subject, not as Korper, the body as a (medical) object. Thematic analysis revealed that few participants describe medical examinations that have occurred over time. For some of them are 
very numerous, especially if they have been suffering from headache for a long time, for others less frequent if the development of migraine attacks is recent. In general they do not take many drugs, except when the pain is unbearable, even if drugs do not always work [10]. This finding is in line with Foiadelli [9] a greater part wait until the pain is moderate/severe or until it is unbearable before taking drugs. Those taking painkillers were ambivalent about the benefits [54].

Conversely, the sickness theme, refers to the influence of the social context on the patients' health status, has received a great deal of attention by participants. Headaches prevent often our respondents from engaging in leisure, sport or recreation. In these cases, respondents react in two different ways: they might go out with friends only if without headache and come back if the pain is too severe, or they might go out with the pain present, take painkillers and try to resist and not give up going out. On the whole, they feel understood by the family, although younger siblings are not always sympathetic to their pain [11]. At school, participants say that they are not always understood by teachers, except for those who suffer from headaches, and overall they report positive experiences with their classmates or close friends. In line with these findings, Donovan and colleagues [11] from interviews with 12 adolescents and their caregivers identified three main themes about their headache experience: the need to be alone, the lack of support from siblings and the feeling of not being understood by others. About this final theme, in the opinion of our sample too, people who do not suffer from migraine headache/headache do not understand what it means to suffer from headache. We might also refer to disorders of the pain matrix, which are often devalued by others. Lonardi also points out that people who have not experienced chronic headache are likely to have experienced a headache and may feel they understand what a "bad headache" is; they may even use the term "migraine" for a bad headache. This is very different from other long-term conditions, for example, epilepsy, as you cannot experience "a bit of" this condition [29].

Another relevant issue concerns the identification of the causes attributed to headache. Most of the interviewees mention study/school, followed by emotional and physical stress, but emotional stress actually concerns school and physical activities carried out. These results are in line with the study by Foiadelli et al. [9], according to which more than half attributed his headache to study/school reasons, to follow emotional stress and similarly physical stress, sight and loud noises. From a clinical point of view it is important to take these aspects into account, especially the emotional stress reported by young patients. In fact, a systematic review by Huguet and colleagues [55] showed that, although there is no causal relationship, some results suggest that the presence of negative emotional states, such as anxiety, depressive symptoms or anxiety, are associated with persistent headache. About causes, the presence of what we have defined "operational algorithm" reminds us of the typical medical stance described by Charon [35]: “We test one diagnostic algorithm after another-and the more seasoned 
we get, the more automatically and under consciously this process occurs-in the effort to categorize this set of events, in the effort to emplot it. The clinician endowed with the gift of plot-and aware of the abysmal echoing of deceptions possible with illness - will search out with great inventiveness and open-endedness and courage (for tolerating the unknown requires it) multiple possible causal relationships among the disparate symptoms and situations that the patient presents". With patients who show attention to researching the causes, it may be useful to deepen this trend, promote the use of a diary (where to mark not only when the attacks come) or become "researchers" of their headaches, enhance their experience in the clinical encounter.

Another relevant theme concerns the strategies applied by patients to deal with pain. In line with previous studies, who have already collected a series of episodes and more or less successful attempts at pain management feel they know what to do to deal with it (isolate themselves from light, noise, and people, have a rest, fall asleep, take medication). Otherwise allow themselves to be advised by the people around them, especially if they have been suffering from headache for much longer than they have [12]. Finally, thinking about the future, half of our interviewees believe that their "headache" will continue for quite some time, especially those patients who experience their family members already suffering from headache/migraine, the other half of the sample hopes, however, that it will improve in the future [10].

There are some limitations to this study that need to be mentioned. First, the qualitative nature of data collected and the limited number of participants prevents the findings being generalised to the overall population of $\mathrm{PPwH}$. However, results provide a point of contact for researchers with the inner world of patients. Through the relationship built with the text, an interpretative process is implemented in the analysis and in the writing the relationship with the text enables a creative-imaginative process. Second, participants were consecutively enrolled on voluntary basis and no stratification was planned with respect to diagnosis, gender or other patients' characteristics, therefore no comparisons between different types of patients could be presented. However, this could be achieved in subsequent studies. Third, the nature of the analysis carried out has been affected by the researchers' subjectivity in identifying, analysing and presenting some aspects detected in the narratives and not others. Both the thematic approach and the structural approach don't contextualise narratives by ignoring historical, interactional and cultural factors [56]. We have not analysed how and how much the research settings and relationships have shaped the way the stories were told. Could this search for an algorithm be something that young participants have absorbed from the relationship with clinicians? Could clinicians learn something from the many possible plots told by PPWH? We need more research to explore, for example, a setting of conversation between peers, outside the clinical settings. Despite these limitations, the current study represents an important first development in our understanding of $\mathrm{PPWH}$ and represents a 
first step toward the use of narratives in clinical practice with $\mathrm{PPwH}$. The application of narrative medicine can improve the possibility to determine the diagnosis and the adequate treatment of paediatric patients by increasing the anamnestic research, identifying the cause of the different types of headaches so that to achieve a more specific diagnosis. the knowledge of psychological and behavioural aspects that can be implied in the onset of migraine or headache can be helpful address more adequately our intervention by avoiding unhelpful pharmacological treatments not indicated for their side effects in this frail category of patients and clarifying the possible psychological nature of pain.

\section{Conclusion}

In conclusion, this study has helped 1) give voice to young headache patients and to describe their experience through narrative; 2) explore how different narrative modes can be used in constructing a sense of the experience of the illness, to construct a map or to place the experience in one's own life trajectory; 3 ) create a prototypic story that neurologists can use with this target group of patients who are not always talkative, to promote narrative and reflection. The effectiveness and usefulness of prototypical narration in eliciting the narrative is to be tested with further studies.

\section{Acknowledgements}

Authors would like to thank all young patients who participated in the study.

\section{Conflicts of Interest}

The authors declare no conflicts of interest regarding the publication of this paper.

\section{References}

[1] Global Burden of Disease Study 2013 Collaborators (2015) Global, Regional, and National Incidence, Prevalence, and Years Lived with Disability for 301 Acute and Chronic Diseases and Injuries in 188 Countries, 1990-2013: A Systematic Analysis for the Global Burden of Disease Study 2013. The Lancet, 386, 743-800.

[2] Steiner, T.J., Birbeck, G.L., Jensen, R.H., Katsarava, Z., Stovner, L.J. and Martelletti, P. (2015) Headache Disorders Are Third Cause of Disability Worldwide. The Journal of Headache Pain, 16, Article No.: 58. https://doi.org/10.1186/s10194-015-0544-2

[3] Lipton, R.B., Manack, A., Ricci, J.A., Chee, E., Turkel, C.C. and Winner, P. (2011) Prevalence and Burden of Chronic Migraine in Adolescents: Results of the Chronic Daily Headache in Adolescents Study (C-dAS). Headache, 51, 693-706. https://doi.org/10.1111/j.1526-4610.2011.01885.x

[4] Wöber-Bingöl, C. (2013) Epidemiology of Migraine and Headache in Children and Adolescents. Current Pain and Headache Reports, 17, Article No.: 341. https://doi.org/10.1007/s11916-013-0341-z

[5] Monastero, R., Camarda, C., Pipia, C. and Camarda, R. (2006) Prognosis of Migraine Headaches in Adolescents: A 10-Year Follow-Up Study. Neurology, 67, 
1353-1356. https://doi.org/10.1212/01.wnl.0000240131.69632.4f

[6] Olesen, J., Bousser, M.G., Diener, H.C., et al. (2006) New Appendix Criteria Open for a Broader Concept of Chronic Migraine. Cephalalgia, 26, 742-746. https://doi.org/10.1111/j.1468-2982.2006.01172.x

[7] Lipton, R.B., Bigal, M.E., Diamond, M., Freitag, F., Reed, M.L. and Stewart, W.F. (2007) Migraine Prevalence, Disease Burden, and the Need for Preventive Therapy. Neurology, 68, 343-349. https://doi.org/10.1212/01.wnl.0000252808.97649.21

[8] Powers, S.W., Patton, S.R., Hommel, K.A. and Hershey, A.D. (2003) Quality of Life in Childhood Migraines: Clinical Impact and Comparison to Other Chronic Illnesses. Pediatrics, 112, e1-e5. https://doi.org/10.1542/peds.112.1.e1

[9] Foiadelli, T., Piccorossi, A., Sacchi, L., De Amici, M., Tucci, M., Brambilla, I., Marseglia, G.L., Savasta, S. and Verrotti, A. (2018) Clinical Characteristics of Headache in Italian Adolescents Aged 11-16 Years: A Cross-Sectional Questionnaire School-Based Study. Italian Journal of Pediatrics, 44, Article No.: 44. https://doi.org/10.1186/s13052-018-0486-9

[10] Walter, S.M. (2017) The Experience of Adolescents Living with Headache. Holistic Nursing Practice, 31, 280-289. https://doi.org/10.1097/HNP.0000000000000224

[11] Donovan, E., Mehringer, S. and Zeltzer, L.K. (2013) A Qualitative Analysis of Adolescent, Caregiver, and Clinician Perceptions of the Impact of Migraines on Adolescents' Social Functioning. Pain Management Nursing, 14, E135-E141. https://doi.org/10.1016/j.pmn.2011.09.002

[12] Skogvold, L. and Magnussen, L.H. (2019) Chronic Tension-Type Headache and Coping Strategies in Adolescents: A Qualitative Interview Study. Physiotherapy Research International, 24, e1778. https://doi.org/10.1002/pri.1778

[13] Kroon Van Diest, A.M., Ernst, M.M., Vaughn, L., Slater, S. and Powers, S.W. (2018) CBT for Pediatric Migraine: A Qualitative Study of Patient and Parent Experience. Headache: The Journal of Head and Face Pain, 58, 661-675. https://doi.org/10.1111/head.13285

[14] Nichols, V.P., Ellard, D.R., Griffiths, F.E., Kamal, A., Underwood, M. and Taylor, S.J. (2017) The Lived Experience of Chronic Headache: A Systematic Review and Synthesis of the Qualitative Literature. BMJ Open, 7, e019929. https://doi.org/10.1136/bmjopen-2017-019929

[15] Holloway, I. and Galvin, K. (2016) Qualitative Research in Nursing and Healthcare. John Wiley and Sons, Hoboken.

[16] Chase, S.E. (2005) Narrative Inquiry. Multiple Lenses, Approaches, Voices. In: Denzin, N.K. and Lincoln, Y.S., Eds., The Sage Handbook of Qualitative Research, 3rd Edition, Sage, Thousand Oaks, 651-679.

[17] Charon, R. (2007) What to Do with Stories: The Sciences of Narrative Medicine. Canadian Family Physician, 53, 1265-1267.

[18] Greenhalgh, T. (1999) Narrative Based Medicine in an Evidence Based World. BMJ, 318, 323-325. https://doi.org/10.1136/bmj.318.7179.323

[19] Greenhalgh, T. and Hurwitz, B. (1998) Narrative Based Medicine Dialogue and Discourse in Clinical Practice. BMJ Books, London

[20] Riley, T. and Hawe, P. (2005) Researching Practice: The Methodological Case for Narrative Inquiry. Health Education Research, 20, 226-236. https://doi.org/10.1093/her/cyg122

[21] Andrews, M., Squire, C. and Tamboukou, M., Eds. (2013) Doing Narrative Research. Sage, Los Angeles. 
[22] Hurwitz, B., Greenhalgh, T. and Skultans, V. (Eds.) (2008) Narrative Research in Health and Illness. John Wiley and Sons, Oxford.

[23] Charon, R. (2017) The Principles and Practice of Narrative Medicine. Oxford University Press, Oxford. https://doi.org/10.1093/med/9780199360192.001.0001

[24] Graffigna, G., Cecchini, I., Breccia, M., Capochiani, E., Della Seta, R., Galimberti, S., Falzetti, F., et al. (2017) Recovering from Chronic Myeloid Leukemia: The Patients' Perspective Seen through the Lens of Narrative Medicine. Quality of Life Research, 26, 2739-2754. https://doi.org/10.1007/s11136-017-1611-8

[25] Scaratti, C., Zorzi, G., Guastafierro, E., Leonardi, M., Covelli, V., Toppo, C. and Nardocci, N. (2020) Long Term Perceptions of Illness and Self after Deep Brain Stimulation in Pediatric Dystonia: A Narrative Research. European Journal of Paediatric Neurology, 28, 61-67. https://doi.org/10.1016/j.ejpn.2020.02.010

[26] Riessman, C. (2002) Analysis of Personal Narratives. In: Gubrium, J. and Holstein, J., Eds., Handbook of Interview Research: Context and Method, Sage Publications, Thousand Oaks, 695-710.

[27] Scaratti, C., Covelli, V., Guastafierro, E., Leonardi, M., Grazzi, L., Rizzoli, P.B., Raggi, A., et al. (2018) A Qualitative Study on Patients with Chronic Migraine with Medication Overuse Headache: Comparing Frequent and Non-Frequent Relapsers. Headache, 58, 1373-1388. https://doi.org/10.1111/head.13385

[28] Kleinman, A. (1988) The Illness Narratives: Suffering, Healing, and the Human Condition. Basic Books, New York.

[29] Lonardi, C. (2007) The Passing Dilemma in Socially Invisible Diseases: Narratives on Chronic Headache. Social Science and Medicine, 65, 1619-1629. https://doi.org/10.1016/j.socscimed.2007.07.007

[30] Riessman, C.K. (2008) Narrative Methods for the Human Sciences. Sage, Thousand Oaks.

[31] Labov, W. (1972) Language in the Inner City: Studies in the Black English Vernacular (No. 3). University of Pennsylvania Press, Philadelphia.

[32] Frank, A.W. (2013) The Wounded Storyteller: Body, Illness, and Ethics. University of Chicago Press, Chicago.

[33] Charon, R., Hermann, N. and Devlin, M.J. (2016) Close Reading and Creative Writing in Clinical Education: Teaching Attention, Representation, and Affiliation. Academic Medicine, 91, 345-350. https://doi.org/10.1097/ACM.0000000000000827

[34] Lamprell, K. and Braithwaite, J. (2019) Reading between the Lines: A Five-Point Narrative Approach to Online Accounts of Illness. Journal of Medical Humanities, 40, 569-590. https://doi.org/10.1007/s10912-019-09553-1

[35] Charon, R. (2008) Narrative Medicine: Honoring the Stories of Illness. Oxford University Press, Oxford.

[36] Labov, W. (1997) Some Further Steps in Narrative Analysis. Journal of Narrative and Life History, 7, 395-415. https://doi.org/10.1075/jnlh.7.49som

[37] Patterson, W. (2013) Narratives of Events; La Bovian Narrative Analysis and Its Limitations. In: Doing Narrative Research, 2nd Edition, Sage, Thousand Oaks, 127. https://doi.org/10.4135/9781526402271.n2

[38] Lieblich, A., Tuval-Mashiach, R. and Zilber, T. (1998) Narrative Research: Reading, Analysis, and Interpretation (Vol. 47). Sage, Thousand Oaks.

https://doi.org/10.4135/9781412985253

[39] Zhang, Y. and Wildemuth, B. (2009) Thematic Content Analysis. In: Applications of Social Research Methods to Questions in Information and Library Science, Libra- 
ries Unlimited, Westport, CT, 308-319.

[40] Braun, V. and Clarke, V. (2006) Using Thematic Analysis in Psychology. Qualitative Research in Psychology, 3, 77-101. https://doi.org/10.1191/1478088706qp063oa

[41] Hsieh, H.F. and Shannon, S.E. (2005) Three Approaches to Qualitative Content Analysis. Qualitative Health Research, 15, 1277-1288. https://doi.org/10.1177/1049732305276687

[42] Clandinin, D.J. and Connelly, F.M. (2000) Narrative Inquiry: Experience and Story in Qualitative Research. Jossey-Bass, San Francisco.

[43] olkinghorne, D. (1988). 1988 Narrative Knowing and the Human Sciences. State University of New York Press, Albany.

[44] Ely, M. (2007) Informing Re-Presentations. In: Clandinin, D., Ed., Handbook of Narrative Inquiry: Mapping a Methodology, Sage, Thousand Oaks, 567598. https://doi.org/10.4135/9781452226552.n22

[45] Todres, L. (2007) Embodied Enquiry: Phenomenological Touchstones for Research, Psychotherapy and Spirituality. Springer.

[46] McNiesh, S.G. (2011) The Lived Experience of Students in an Accelerated Nursing Program: Intersecting Factors That Influence Experiential Learning. Journal of Nursing Education, 50, 197-203. https://doi.org/10.3928/01484834-20101029-03

[47] Bury, M. (1982) Chronic Illness as Biographical Disruption. Sociology of Health and Illness, 4, 167-182. https://doi.org/10.1111/1467-9566.ep11339939

[48] Palacios-Ceña, D., Talavera, B., Gómez-Mayordomo, V., García-Azorín, D., Gallego-Gallego, M., Guerrero, Á.L. and Cuadrado, M.L. (2020) The Day My Life Changed: A Qualitative Study of the Experiences of Patients with New Daily Persistent Headache. Headache, 60, 124-140. https://doi.org/10.1111/head.13712

[49] Leveälahti, H., Tishelman, C. and Öhlén, J. (2007) Framing the Onset of Lung Cancer Biographically: Narratives of Continuity and Disruption. Psycho-Oncology, 16, 466-473. https://doi.org/10.1002/pon.1080

[50] Covelli, V., Cerniauskaite, M., Leonardi, M., Sattin, D., Raggi, A. and Giovannetti, A.M. (2014) A Qualitative Study on Perceptions of Changes Reported by Caregivers of Patients in Vegetative State and Minimally Conscious State: The "Time Gap Experience". The Scientific World Journal, 2014, Article ID: 657321. https://doi.org/10.1155/2014/657321

[51] McAdams, D.P. and McLean, K.C. (2013) Narrative Identity. Current Directions in Psychological Science, 22, 233-238. https://doi.org/10.1177/0963721413475622

[52] Pasupathi, M. and Hoyt, T. (2009) The Development of Narrative Identity in Late Adolescence and Emergent Adulthood: The Continued Importance of Listeners. Developmental Psychology, 45, 558-574. https://doi.org/10.1037/a0014431

[53] Larsson, B. and Fichtel, Å. (2012) Headache Prevalence and Characteristics among School Children as Assessed by Prospective Paper Diary Recordings. The Journal of Headache and Pain, 13, 129-136. https://doi.org/10.1007/s10194-011-0410-9

[54] Blume, H.K. (2017) Childhood Headache: A Brief Review. Pediatric Annals, 46, e155-e165. https://doi.org/10.3928/19382359-20170321-02

[55] Huguet, A., Tougas, M.E., Hayden, J., McGrath, P.J., Chambers, C.T., Stinson, J.N. and Wozney, L. (2016) Systematic Review of Childhood and Adolescent Risk and Prognostic Factors for Recurrent Headaches. The Journal of Pain, 17, 855-873. https://doi.org/10.1016/j.jpain.2016.03.010

[56] Riessman, C.K. (2005) Narrative Analysis. In: Narrative, Memory and Everyday Life, University of Huddersfield, Huddersfield, 17. 